\title{
Evaluation of post-extraction bleeding in patients taking low dose aspirin
}

Dr. Sajid Hasan¹, Dr. Mahmuda Akhter², Dr. Saeed Hossain Khan³, Dr. Dilruba Sharminn, Dr. Md. Manjurul Karim5, Dr. Rifat Rahman ${ }^{6}$

\section{AFFILIATION:}

1. Dr. Sajid Hasan

BDS, FCPS (Oral \& Maxillofacial Surgery)

Assistant Professor, Ibrahim Medical College

Junior Consultant, Department of Dental Surgery, BIRDEM General Hospital

2. Dr. Mahmuda Akhter

BDS, MS, FCPS (Oral \& Maxillofacial surgery)

Associate Professor

Department of Oral \& Maxillofacial surgery, BSMMU

3. Dr. Saeed Hossain Khan

BDS, FCPS (Orthodontics)

Associate Professor, Ibrahim Medical College

Consultant, Department of Dental Surgery, BIRDEM General Hospital

4. Dr. Dilruba Sharmin

BDS, MPH (NIPSOM)

5. Dr. Md. Manjurul Karim

BDS, MPH

Lecturer, Department of Oral \& Maxillofacial surgery

Marks Medical College (Dental Unit)

6. Dr. Rifat Rahman

BDS, MPH, MSc Oral Medicine

Senior Lecturer, Department of Periodontology, Oral Pathology \& Oral Medicine, Update dental college \& hospital, Dhaka, Bangladesh

\section{Article info.}

Received: $17^{\text {th }}$ January, 2019

Accepted: $2^{\text {nd }}$ February, 2019

Volume: 9, Issue-1 April, 2019

\section{DOI: https://doi.org/10.3329/updci.v9i1.41204}

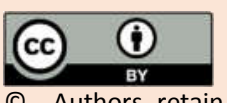

(C) Authors retain copyright and grant the journal right of first publication with the work simultaneously licensed under Creative Commons Attribution License CC - BY 4.0 that allows others to share the work with an acknowledgment of the work's authorship and initial publication in this journal.

https://creativecommons.org/licenses/by/4.0/

Publisher: Update Dental College, Dhaka, Bangladesh

Web: www.updatedentalcollege.edu.bd

E-mail: updcj@hotmail.com

* Corresponding Author

Dr. Sajid Hasan

BDS, FCPS (Oral \& Maxillofacial Surgery)

Assistant Professor, Ibrahim Medical College

Junior Consultant, Dept. of Dental Surgery, BIRDEM General Hospital

Ph: 01717054471, E-mail: dr. sazidhasan@gmail.com

\section{Citation}

Dr. Sajid Hasan, Dr. Mahmuda Akhter, Dr. Saeed Hossain Khan, Dr. Dilruba Sharmin, Dr. Md. Manjurul Karim, Dr. Rifat Rahman. Evaluation of post-extraction bleeding in patients taking low dose aspirin.Update Dental College Journal. 2019 April; 9(1): 32-36. DOI: https://doi.org/10.3329/updcj.v9i1.41204

\begin{abstract}
Background: Acetylsalicylic acid (ASA) generically known as Aspirin is an analgesic, antipyretic, anti-inflammatory and also an antiplatelet drug. In order to avoid excessive bleeding and to be on the safer side, dentists have traditionally advised their patients to stop taking aspirin before extraction of teeth although this surgical procedure can be done without cessation of aspirin intake.

Objective: The purpose of the study was to assess the necessity of interrupting aspirin therapy prior to dental extraction.

Materials and Methods: A cross sectional study was conducted in November 2015 at outpatient department of dentistry, BIRDEM Hospital, Dhaka. Sample of 50 patients who took low dose aspirin $(75 \mathrm{mg})$ once daily were purposely selected for this study. The blood pressure of all the subjects was recorded preoperatively. The extractions were done atraumatically under local anesthesia using $2 \%$ lidocaine with 1:100,000 epinephrine. A gelatin sponge piece was placed in socket and closed by atraumatic silk. The subjects were instructed to apply pressure pack with sterile gauze for $30 \mathrm{~min}$. Evaluation was done in every 10 minutes for 30 minutes.

Results: Among 50 patients, $82.0 \%$ patients were suffering from IHD. Simple extraction was done in $92.0 \%$ of patients while the remaining extractions were done surgically. $68 \%$ was managed by pressure pack and gelatin sponge while $26.0 \%$ were managed by pressure pack only. According to Post-extraction bleeding, it was found that the bleeding time was $10 \mathrm{~min}$ in case of $94 \%$ patients while only $2 \%$ showed 30 minutes of bleeding time.

Conclusion: The study revealed that it is not necessary to alter or stop aspirin therapy and local hemostatic measures are sufficient to control bleeding. Therefore it can be assumed that extraction can be done without cessation of low dose aspirin and avoiding the life threatening issues.
\end{abstract}

Key words:

Acetylsalicylic acid (ASA), Aspirin, Dental Extraction, Bleeding, IHD (Ischemic Heart Disease) Thromboembolism.

Introduction:

Cardiac patients on aspirin therapy may require extractions for their diseased teeth. It is a common practice among physicians and treating surgeons to stop aspirin prior to tooth extraction because of fear of bleeding complications. This practice often predisposes the patient to adverse thromboembolic events. This practice is based on theoretical risk of bleeding and on isolated case reports of excessive bleeding with aspirin therapy. The current consensus and recommendations are in favor of continuing aspirin therapy during simple tooth extraction as the bleeding complication incidence is very less and if it occurs can be controlled efficiently with local hemostasis measures. ${ }^{1}$

In recent years, most studies do not recommend reducing or interrupting anticoagulation,or replacing it with heparin, prior to tooth extraction - provided therapeutic international normalized ration (INR) levels are maintained, with emphasis on the application of local measures such as antifibrinolytic agents, for the control of hemostasia. ${ }^{2}$ 
Acetylsalicylic acid (ASA) generically known as aspirin is used clinically as an analgesic, antipyretic, anti-inflammatory agents and as a medication to prevent platelet aggregation. It is indicated for long term use in patients susceptible to the formation of emboli, such as patients who have suffered from stroke, angina or myocardial infarctions (Anonymous, 2002). ${ }^{3}$ Aspirin blocks the synthesis of thromboxane $\mathrm{A} 2$ by irreversibly inhibiting cyclooxygenase 1 , thereby diminishing platelet aggregation. It widely used in low dose as an anti-platelet agent in patients having myocardial ischemia or risk of stroke. ${ }^{4}$ Though the incidence of spontaneous bleeding is very rare according to studies but it can occur. Following dental surgical procedure, hemorrhagic mishaps are rare except for few cases of required platelet transfusions. ${ }^{5}$

Nowadays it is recommended to go for various dental procedures without interrupting aspirin therapy $\mathrm{y}^{6,7}$ as inhibiting antiplatelet therapy has risk for developing thrombo-embolic event. ${ }^{8,9}$

Dental Literature regarding Increased Bleeding with Use of Aspirin Therapy

Literature review reveals that clinical trials involving dental extraction and anti platelet therapy started in 1970 and it is still going on. Studies conducted in 1970s by Lemkin et al and Mc Gaul et al have documented that there is increased postoperative bleeding after dental extraction and recommended to discontinue aspirin. Few authors recommended stopping aspirin 7 days preoperatively. Few other authors recommended stopping aspirin for 3 days or lesser than that. The rationale for such recommendation is that, after 3 days of interruption of aspirin, sufficient number of newer platelets will be present in the circulation for effective hemostasis. ${ }^{10}$

Dental Literature regarding Safety of Continued Aspirin Therapy prior to Tooth Extraction

Brennan et al. reviewed the literature regarding the management of patients on aspirin requiring oral surgical procedures. They also recommended continuation of aspirin during dental extractions based on results of studies with high level of evidences. Gaspar et al. concluded that ambulatory oral surgical procedures can be performed in patients on aspirin therapy as hemostasis posed no problem. Hence, they recommended continuation of aspirin therapy without interruption prior to oral surgical procedures. Oral Medicine and Oral Surgery Francophone Society conducted a literature review and gave recommendations for management of patients on antiplatelet therapy based on the agreement among professionals in the field. The society stated that interruption of antiplatelet therapy prior to dental procedures is unnecessary. The risk of bleeding is very low and local hemostatic measures are usually successful.

33 | P a g e
Allard et al. stated that the review of available literature is in favor of not stopping aspirin or clopidogrel in case of simple dental surgical procedures. Krishnan et al. in a prospective clinical study performed extraction procedures on normal patients and ptients who stopped aspirin preoperatively [25 subjects in each group]. Simple intra-alveolar extractions were performed and hemostasis was achieved with wet gauze pressure pack for 30 minutes. ${ }^{1}$ In contrast to the previous studies, Madan et al and Valerin et al in their study have stated that there is increased risk of thrombotic outcomes with the discontinuation of low dose aspirin therapy. Ardekian et al found that a daily dose of $100 \mathrm{mg}$ of Aspirin did not increase the bleeding during tooth extraction. There was a statistical significance in bleeding time between the groups that continued and withdrew aspirin before tooth extraction. Thus the patients need not stop taking Aspirin before dental surgery, provided that heamorrhagic risk is not greater than thromboembolic risk associated by interrupting the dose of the drug. According to Crispian Scully et al., for uncomplicated forcep extraction of 1 to 3 teeth there is no need to interfere the aspirin dose. ${ }^{7}$ Matocha concluded in his study that the risk of bleeding after dental extraction is minimal in the patients with aspirin therapy and did not exceed $0.2-2.3 \%{ }^{11}$ Napeñas et al conducted a literature review of bleeding complications in dental patients taking antiplatelet agents in 2013. The authors concluded there is no need to stop single or dual antiplatelet therapy for invasive dental procedures, and local measures are adequate for hemostasis. ${ }^{12}$

In department of dentistry, BIRDEM, traditionally aspirin therapy was interrupted for 3-5 days before extraction of tooth. The purpose of this study was to assess whether safe extraction procedure can be carried out without any alteration in aspirin therapy by assessment of post extraction bleeding time in case of cardiac patients.

Methods:

A cross sectional study was conducted in November 2015 with informed written consent from patients and their parents in BIRDEM Hospital, Dhaka. 50 patients were included as the sample who were taking low dose aspirin $(75 \mathrm{mg})$ once daily Data collection method included dental clinical examination, anthropometric measurements and a questionnaire comprised of some questions related to their age, sex, height, weight, medical history and extraction of teeth. The blood pressure of all the subjects were recorded preoperatively. The extractions were done least traumatically as possible under local anaesthesia using 2\% lidocaine with 1:100,000 epinephrine. A gelatin sponge piece was placed in socket and closed by atraumatic silk which was removed after 5 days. The subjects were instructed to apply pressure pack on a piece of sterile gauze for 30 minutes. Evaluation was done in every 10

Website: https://www.banglajol.info/index.php/UpDCJ 
minutes during the 30 minutes time period. If bleeding stopped, then they were discharged with advice and contact information. Patients were also advised to provide information about any further incident of post-operative bleeding with accurate timing. Follow up was given contacted by phone $12 \mathrm{~h}$, $24 \mathrm{~h}, 48 \mathrm{~h}$ and 5 days post-operatively. If there was any bleeding after initial 30 minutes, the patient was re-examined, managed accordingly and evaluated after $30 \mathrm{~min}$. Patients were discharged after being that homeostasis has been achieved. If the subjects reported over the phone that bleeding still persisted, patient was instructed to return for further evaluation and management. Data from each procedure was collected and then statistical analysis was done by using SPSS.

\section{Results:}

According to this study, out of 50 patients, 28 were male and 22 were female (Table 1). Between the age range of $40-85$, $40 \%$ patient belonged to age group 51-60 years (table 2).

Majority of the patients were suffering from IHD (82\%). (Table 3) Extractions were done in few cases admitted in hospital while most of the extractions were done in outdoor (Table 4). Teeth were extracted by local anesthetic infiltration in 36 patients while the remaining extractions were done by infiltration and nerve block (Table 5).

Majority (46/50) of extractions were simple and hemostasis was achieved by pressure pack and gelatin sponge in 34 cases (Table 6). 2 case required thermocoagulation to arrest bleeding along with pressure pack and gelatin sponge (Table 7).

More than $50 \%$ extractions were done from lower mandibular teeth especially the posterior molars. Among them, there were 13 cases of $3^{\text {rd }}$ molar extractions (Table 8, 9 and 10). Hemostasis was achieved within 10 minutes after extraction in majority of the cases $(47 / 50)$ while the remaining 3 had post extraction bleeding time of more than 10 minutes (Table 11).

Table 1 shows the distribution of the study patients by sex.

\begin{tabular}{|l|c|c|}
\hline Sex & Number of patients & Percentage \\
\hline Male & 28 & 56.0 \\
\hline Female & 22 & 44.0 \\
\hline Total & 50 & 100.0 \\
\hline \hline Male: female ratio & & $1.3: 1$ \\
\hline
\end{tabular}

Table- 2 shows the distribution of the study patients by age $(n=50)$

\begin{tabular}{|c|c|c|c|}
\hline Age group & Frequency & Percentage (\%) & Mean \pm SD \\
\hline $\mathbf{4 0 - 5 0}$ & 5 & 10.0 & $\mathbf{6 1 . 6 0 \pm 9 . 4 5}$ \\
$-\mathbf{6 0}$ & 20 & 40.0 & $\mathbf{( 4 0 - 8 5 )}$ \\
\hline $\mathbf{6 1 - 7 0}$ & 18 & 36.0 & \\
\hline$>\mathbf{7 0}$ & 7 & 17.0 & \\
\hline \hline Total & $\mathbf{5 0}$ & $\mathbf{1 0 0 . 0}$ & \\
\hline
\end{tabular}

34 | P a g e
Table 3 shows the distribution of study subjects by medical history

\begin{tabular}{|l|c|c|}
\hline Medical history & Frequency & Percentage (\%) \\
\hline Stroke & 3 & 6.0 \\
\hline IHD & 41 & $\mathbf{8 2 . 0}$ \\
\hline \hline HTN & 6 & 12.0 \\
\hline
\end{tabular}

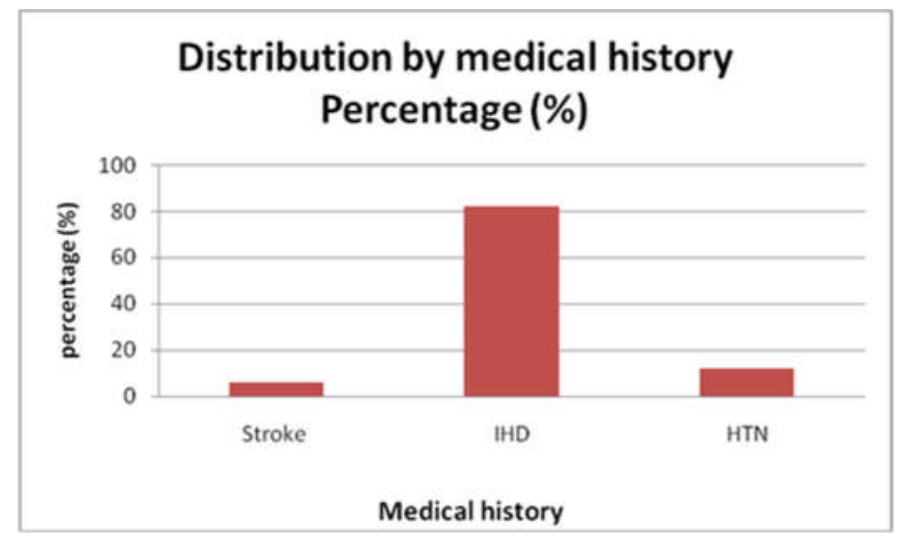

Figure-1: Distribution of the study subjects by type of patients $(n=50)$

Table 4 showed the distribution of hospital admitted patients and those managed in outdoor

\begin{tabular}{|l|c|c|}
\hline Type of patients & Frequency & Percentage (\%) \\
\hline Hospitalized & 8 & 16.0 \\
\hline Outdoor management & 42 & $\mathbf{8 4 . 0}$ \\
\hline \hline Total & $\mathbf{5 0}$ & $\mathbf{1 0 0 . 0}$ \\
\hline
\end{tabular}

Table 5 shows the distribution of the study subjects according to type of anaesthesia

\begin{tabular}{lccc}
\hline Type of anaesthesia & Frequency & Percentage (\%) \\
\hline Infiltration & 36 & $\mathbf{7 2 . 0}$ \\
\hline Infiltration + Nerve block & 14 & $\mathbf{2 8 . 0}$ \\
\hline \hline Total & $\mathbf{5 0}$ & $\mathbf{1 0 0 . 0}$ \\
\hline
\end{tabular}

Table 6 shows that the distribution of the study subjects by type of extraction

\begin{tabular}{lcc}
\hline Type of extraction & Frequency & Percentage (\%) \\
\hline Simple & 46 & $\mathbf{9 2 . 0}$ \\
Surgical & 4 & $\mathbf{8 . 0}$ \\
\hline \hline Total & $\mathbf{5 0}$ & $\mathbf{1 0 0 . 0}$ \\
\hline
\end{tabular}


Table-7 shows the distribution of the study subjects by primary hemostatic care

\begin{tabular}{lcc|}
\hline Primary hemostatic care & Frequency & Percentage (\%) \\
\hline Pressure pack & 13 & $\mathbf{2 6 . 0}$ \\
\hline $\begin{array}{l}\text { Pressure pack + Gelatin } \\
\text { sponge }\end{array}$ & 34 & 68.0 \\
Pressure pack + Suturing & 1 & $\mathbf{2 . 0}$ \\
Pressure pack + Gelatin & 2 & $\mathbf{4 . 0}$ \\
sponge + Thermo coagulation & & $\mathbf{1 0 0 . 0}$ \\
\hline \hline Total & $\mathbf{5 0}$ & \\
\hline
\end{tabular}

Distribution of the patients by primary hemostatic care Percentage (\%)

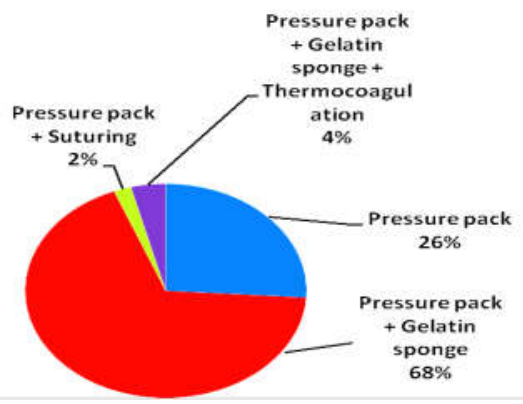

Table- 8 shows the distribution of the study subjects by ARCH involvement

$\begin{array}{lcc}\text { ARCH involvement } & \text { Frequency } & \text { Percentage (\%) } \\ \text { Maxillary } & 18 & 36.0 \\ \text { Mandibular } & 28 & 56.0 \\ \text { Both mandibular and } & 4 & 8.0 \\ \text { maxillary } & & \\ \text { Total } & 50 & 100.0\end{array}$

Table-9 shows the distribution of the study subjects by side involvement

$\begin{array}{lcc}\text { Side involvement } & \text { Frequency } & \text { Percentage (\%) } \\ \text { Right } & 22 & 44.0 \\ \text { Left } & 25 & 50.0 \\ \text { Both } & 3 & 6.0 \\ \text { Total } & 50 & 100.0\end{array}$

Table-10 shows the distribution of the study subjects by type of teeth

$\begin{array}{lcc}\text { Type of teeth } & \text { Frequency } & \text { Percentage (\%) } \\ \text { Central incisor } & 5 & 10.0 \\ \text { Lateral incisor } & 1 & 2.0 \\ \text { Canine } & 3 & 6.0 \\ \mathbf{1}^{\text {st }} \text { Premolar } & 6 & 12.0 \\ \mathbf{2}^{\text {nd }} \text { Premolar } & 6 & 12.0 \\ \mathbf{1}^{\text {st }} \text { Molar } & 14 & 28.0 \\ \mathbf{2}^{\text {nd }} \text { Molar } & 13 & 26.0 \\ \mathbf{3}^{\text {rd }} \text { Molar } & 13 & 26.0\end{array}$

Table 11 shows the distribution of the study subjects according to Postextraction bleeding time

\begin{tabular}{lcc}
\hline Timing of homeostasis & Frequency & Percentage (\%) \\
\hline $10 \mathrm{~min}$ & 47 & 94.0 \\
$20 \mathrm{~min}$ & 2 & 4.0 \\
$30 \mathrm{~min}$ & 1 & 2.0 \\
\hline \hline Total & 50 & 100.0 \\
\hline
\end{tabular}

35 | P a g e

\section{Discussion:}

Routine dental extractions can be safely performed in patients on long-term antiplatelet medication, with no interruption or alteration of their medication. Such patients do not have an increased risk of prolonged or excessive postoperative bleeding. Many authors recommended not stopping aspirin which is also recommended in our present study. Madan et al. (2005) in a study included 51 patients (32 males, 19 females), ranging in age from 45 to 70 years. ${ }^{13}$ Similarly findings found in this present study, Male : female ratio 1.3:1, ranging in age from $51-60$ years.

In 2009, Nasser found that, bleeding occurred in about $2 \%$ of patients in both the control and study groups following surgical extractions after $12 \mathrm{~h}$. However, after $48 \mathrm{~h}$ both groups demonstrated no bleeding. Brennan et al. (2008) studied 36 patients divided into two groups: Group 1 patients received $325 \mathrm{mg}$ ASA daily and Group 2 served as control. They investigated the bleeding time. No significant differences were found between the two groups in the bleeding time. They recommended not stopping ASA before the surgical procedure. The issue of significant blood loss during minor oral surgery was examined by Patridge et al. (2008) who concluded that patients who had taken ASA demonstrated blood loss $1.97 \mathrm{~g}$ per unit of surgery compared to $1.96 \mathrm{~g}$ per unit of surgery in the control group. Therefore, no significant statistical difference between the two groups was found. This finding supported the notion that ASA should not be stopped before minor oral surgery. ${ }^{3}$

Ardekian et al found that a daily dose of $100 \mathrm{mg}$ of Aspirin did not increase the bleeding during tooth extraction. There was a statistical significance in bleeding time between the groups that continued and withdrew aspirin before tooth extraction. However, both groups were within the normal bleeding time range, and in both groups, a local hemostatic method was sufficient to control bleeding. No episodes of uncontrolled intraoperative or postoperative bleeding had been noted. Sonksen et al showed that increase in bleeding time caused by daily aspirin dose of $300 \mathrm{mg}$ did not exceed the normal limits in patients. Thus the patients need not stop taking Aspirin before dental surgery. ${ }^{7}$

Allard et al. stated that the review of available literature is in favor of not stopping aspirin or clopidogrel in case of simple dental surgical procedures. ${ }^{1}$ Similarly in this present study, $92.0 \%$ was simple extraction was done without withdrawl of the aspirin therapy.

Website: https://www.banglajol.info/index.php/UpDCJ 
Nabeel (2015) found that oral hemostatic measures can be taken to control bleeding after tooth extraction by suturing the socket and by packing gauze bite firmly for 15-30 minutes. ${ }^{10}$ Krishnan et al. in a prospective clinical study performed extraction procedures on patients taking aspirin, on patients who stopped aspirin preoperatively, and in normal patients [25 patients in each group]. Simple intra-alveolar extractions were performed and hemostasis was achieved with wet gauze pressure pack for 30 minutes. Patients were reassessed after 30 minutes for any persistent bleeding. After ensuring that hemostasis patients were discharged, patients were advised to report back in case of postoperative bleeding. ${ }^{1}$ Similarly in this present study, in case of maximum patients around $68 \%$ bleeding was controlled by pressure pack and gelatin sponge.

Cañigral et al. conducted a study involving simple and surgical extractions in patients on antithrombotic therapy. The antithrombotic therapy comprises aspirin, clopidogrel, aspirin + clopidogrel, nonsteroidal anti-inflammatory drugs (NSAIDs), or low molecular weight heparin (LMWH). In 92\% of instances, bleeding was stopped within 10 minutes with pressure alone. Only $8 \%$ of cases of moderate hemorrhage were easily managed by local hemostatic measures. ${ }^{1}$

Dattatraya ( 2014 ) concluded a study by chi-square test where the bleeding time increased $(3.8 \pm 0.75)$ in group A patients continued with the aspirin therapy where as group B discontinued aspirin. Similarly, the clotting time increased in group B patients and decreased in group A patients. But in both the groups, bleeding and clotting time remained within normal limits. ${ }^{11}$ Preoperative values were within normal limits for all patients. Aspirin was not stopped for a single patient. There was no excessive intraoperative bleeding in all cases except 1 ; there was no postoperative bleeding in all cases. ${ }^{13}$ Similarly findings found in this present study, the bleeding time is $10 \mathrm{~min}$ in case of $94 \%$ patient and only $2 \%$ shows $30 \mathrm{~min}$ of bleeding time.

Conclusion: It is important to balance the benefits and risks regarding whether dental treatment is continued with or without stopping the medication. Based on the clinical review of patient, it can be concluded that dental extractions may be safely performed in patients receiving aspirin therapy to avoid the thrombotic risk. Existing data indicates there is no necessity to alter or stop these drugs and that local hemostatic measures are sufficient to control bleeding.

\section{References:}

1. Gaurav Verma. Dental Extraction Can Be Performed Safely in Patients on Aspirin Therapy: A Timely Reminder; ISRN Dentistry(International Scholarly Research Notices) ,Volume (2014), Article ID 463684, 11 pages. https://doi.org/10.1155/2014/463684

Available from: https://www.hindawi.com/journals/isrn/2014/463684/

2. Jiménez $Y$, Poveda R, Gavaldá C, Margaix $M$, Sarrión G. An update on the management of anticoagulated patients programmed for dental extractions and surgery. Med Oral Patol Oral Cir Bucal. 2008 Mar 1;13(3):E176-9.

Available from: https://www.ncbi.nlm.nih.gov/pubmed/18305438

4. Kumar A and P. C.Christopher.Acute Coronary Syndromes: Diagnosis and Management, Part I. Mayo Clin Proc. 2009;84(10):917-938.

https://doi.org/10.4065/84.10.917

PMid:19797781 PMCid:PMC2755812

5. Wahl M. Anticoagulants and Antiplatelet Drugs in Dentistry: Stop the Interruption. PennWell Publications, August 2013

Available from: http://www.rdhmag.com/content/dam/rdh/printarticles/Volume\%2033/Issue\%208/1307cei Wahl web.pdf

6. Scully C. Oral surgery in patients on anticoagulant therapy. Oral Surg Oral Med Oral Pathol Oral Radiol Endod 2002; 94:57-64. https://doi.org/10.1067/moe.2002.123828

PMid:12193895

7. Dr. Madhulaxmi. M, Dr. P.U. Abdul Wahab. Can Aspirin Be Continued During Dental Extraction? International Journal Of Pharmacy And Pharmaceutical Sciences 2014; Vol 6 (1)

8. Collet JP, Montalescot G, Blanchet B, Tanguy ML, Golmard JL, Choussat R, et al. Impact of prior use or recent withdrawal of oral antiplatelet agents on acute coronary syndromes Circulation 2004; 110:2361-7. https://doi.org/10.1161/01.CIR.0000145171.89690.B4

9. Ferrari E, Benhamou M, Cerboni P, Marcel B. Coronary syndromes following aspirin withdrawal: a special risk for late stent thrombosis. J Am Coll Cardiol 2005; 45:456-9. https://doi.org/10.1016/j.jacc.2004.11.041

PMid:15680728

10. Nabeel Ahmed*, Dhivya Lakshmi M, Nabeel Nazar M; 2015; Aspirin and Dental Extractions: Still A Myth? International Journal of Pharmaceutical and Clinical Research, 7(2): 109-112, ISSN- 09751556

11. Dattatraya A Darawade, Santosh Kumar, Khushboo Desai, Basit Hasan, Anuj Vasantray Mansata; 2014 Nov; Influence of aspirin on post-extraction bleeding - A clinical study, J Int Soc Prev Community Dent.; 4(Suppl 1): S63S67. https://doi.org/10.4103/2231-0762.144602

12. Nape-as JJ, Oost FC, Degroot A, et al. Review of postoperative bleeding risk in dental patients on antiplatelet therapy. Oral Surg Oral Med Oral Pathol Oral Radiol. 2013;115:491-499.

https://doi.org/10.1016/j.0000.2012.11.001 PMid:23332510

13. Madan GA, Madan SG, Madan G, Madan AD; Minor oral surgery without stopping daily low-dose aspirin therapy: a study of 51 patients, J Oral Maxillofac Surg. 2005 Sep;63(9):1262-5.

https://doi.org/10.1016/j.joms.2005.05.164

Available from: https://www.ncbi.nlm.nih.gov/pubmed/16122588

14. Krishnan B, Shenoy NA, Alexander M. Exodontia and antiplatelet therapy. J Oral Maxillofac Surg. 2008 Oct;66(10):2063-6 https://doi.org/10.1016/j.joms.2008.06.027 